\title{
Resistance to Long-term Bacterial Biofilm Formation Based on Hydrolysis-Induced Zwitterions Material with Biodegradable and Self-healing Properties
}

Jun Ma ${ }^{\mathrm{a}}$, Weifeng Lin ${ }^{\mathrm{a}}$, Liangbo Xu${ }^{\mathrm{a}}$, Sihang Liu ${ }^{\mathrm{a}}$, Weili Xue ${ }^{\mathrm{a}}$, Shengfu Chen ${ }^{\mathrm{a}}$, b, c *

a State Key Laboratory of Chemical Engineering, Department of Chemical and Biological Engineering, Zhejiang University, Hangzhou 310027, P. R. China

b Institute of Zhejiang University-Quzhou, Quzhou 324000, China

c Jiangsu Collaborative Innovation Center of Biomedical Functional Materials, Jiangsu Key Laboratory of Biomedical Materials, College of Chemistry and Materials Science, Nanjing Normal University, Nanjing 210046, China

* To whom correspondence should be addressed: E-mail: schen@zju.edu.cn; 


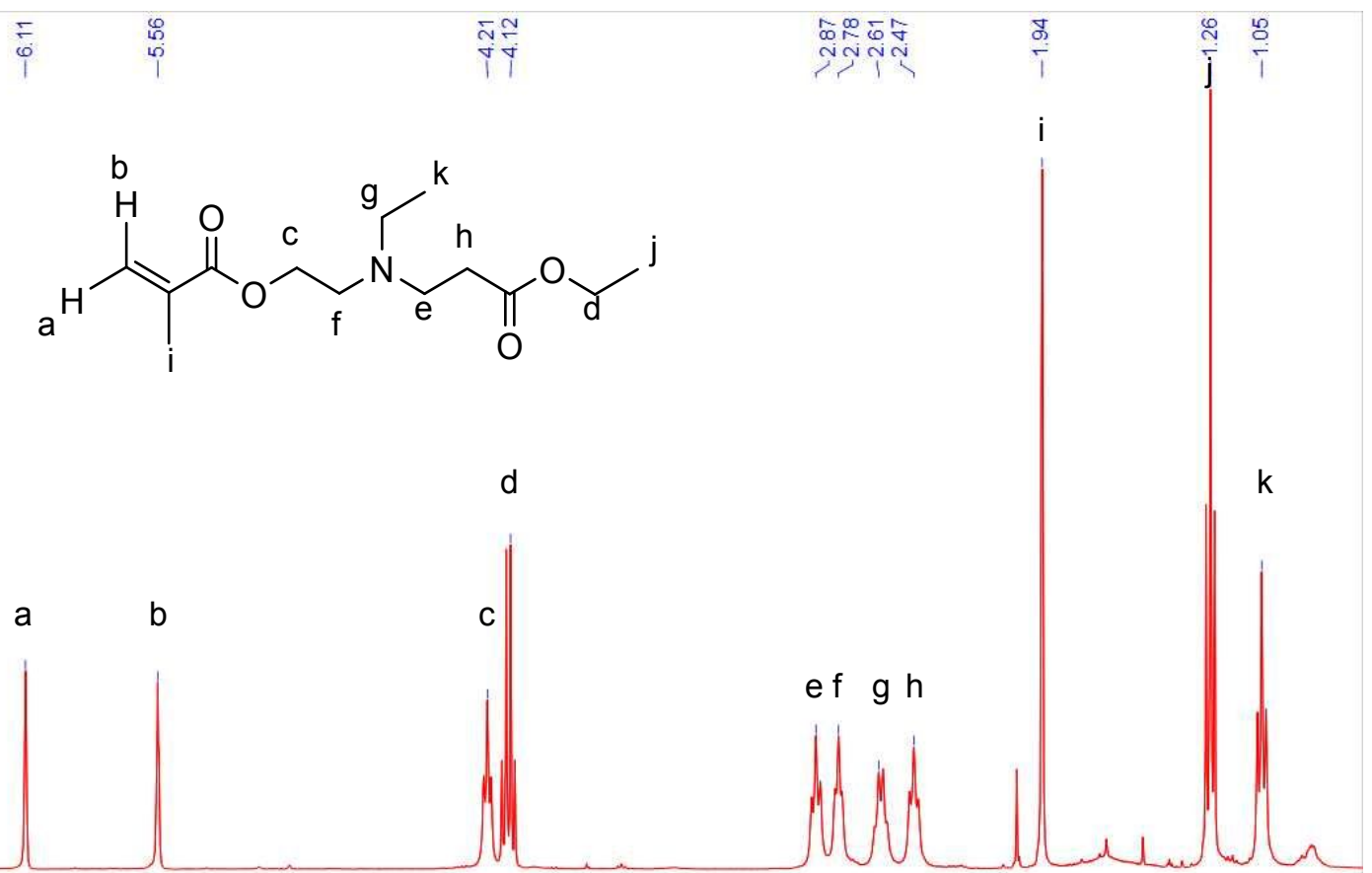

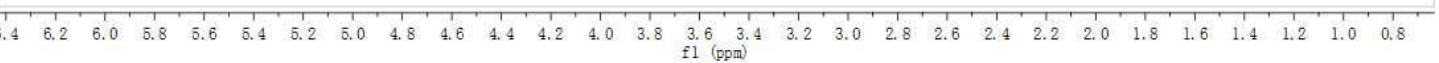

Figure S1. ${ }^{1} \mathrm{H}$ NMR spectra of ECBEMA in $\mathrm{CDCl}_{3}$

The ${ }^{1} \mathrm{H}$ NMR spectra of ECBEMA was shown in Figure S1. ${ }^{1} \mathrm{H}$ NMR (400 MHz, $\left.\mathrm{CDCl}_{3}, \mathrm{ppm}\right): 6.11(\mathrm{~m}, 1 \mathrm{H}), 5.56(\mathrm{~m}, 1 \mathrm{H}), 4.21(\mathrm{t}, 2 \mathrm{H}), 4.12(\mathrm{q}, 2 \mathrm{H}), 2.87(\mathrm{t}, 2 \mathrm{H}), 2.78$ (t, 2H), $2.61(\mathrm{t}, 2 \mathrm{H}), 2.47(\mathrm{~s}, 3 \mathrm{H}), 1.94(\mathrm{~s}, 3 \mathrm{H}), 1.26(\mathrm{t}, 3 \mathrm{H}), 1.05(\mathrm{t}, 3 \mathrm{H})$. 


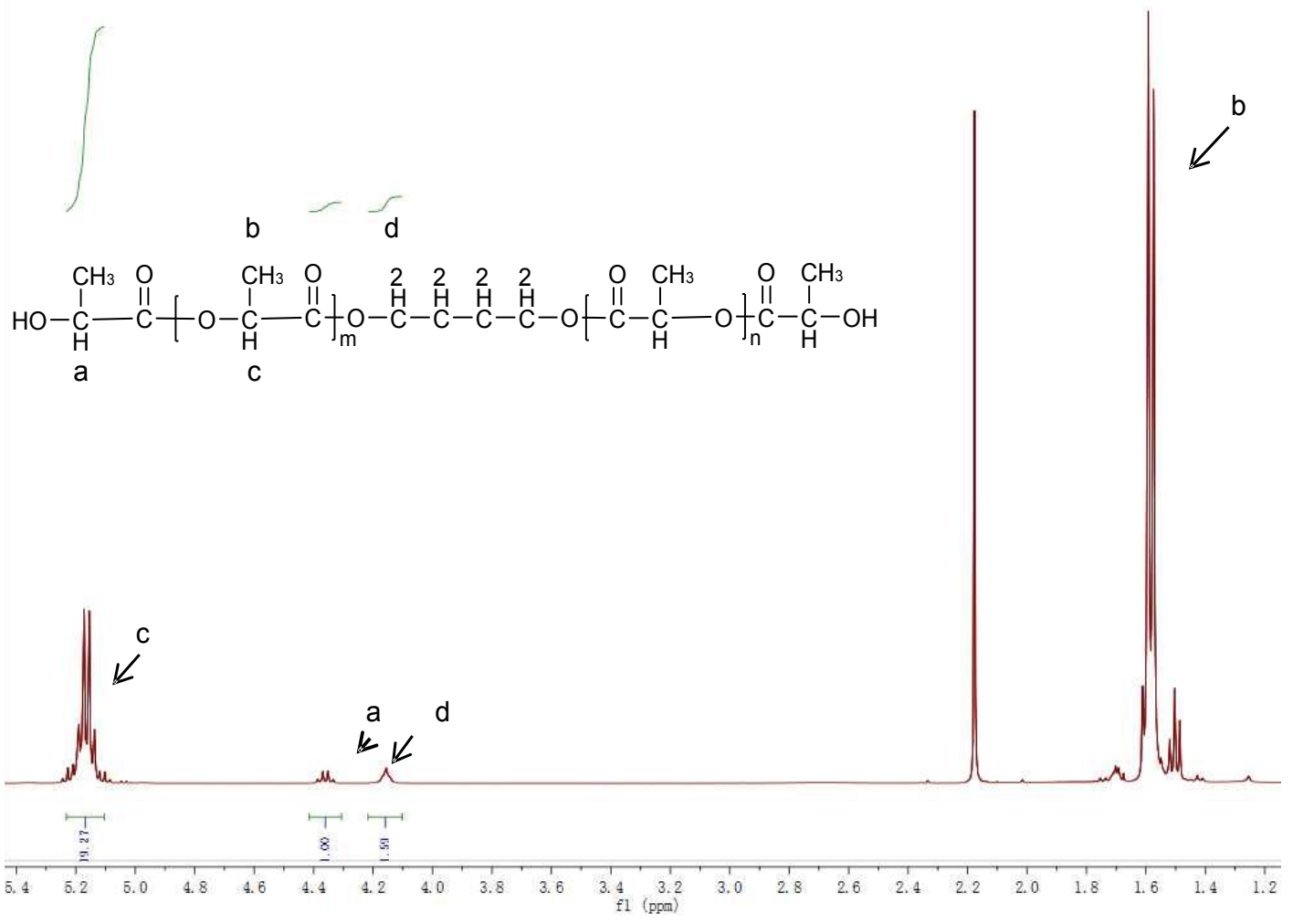

(a)

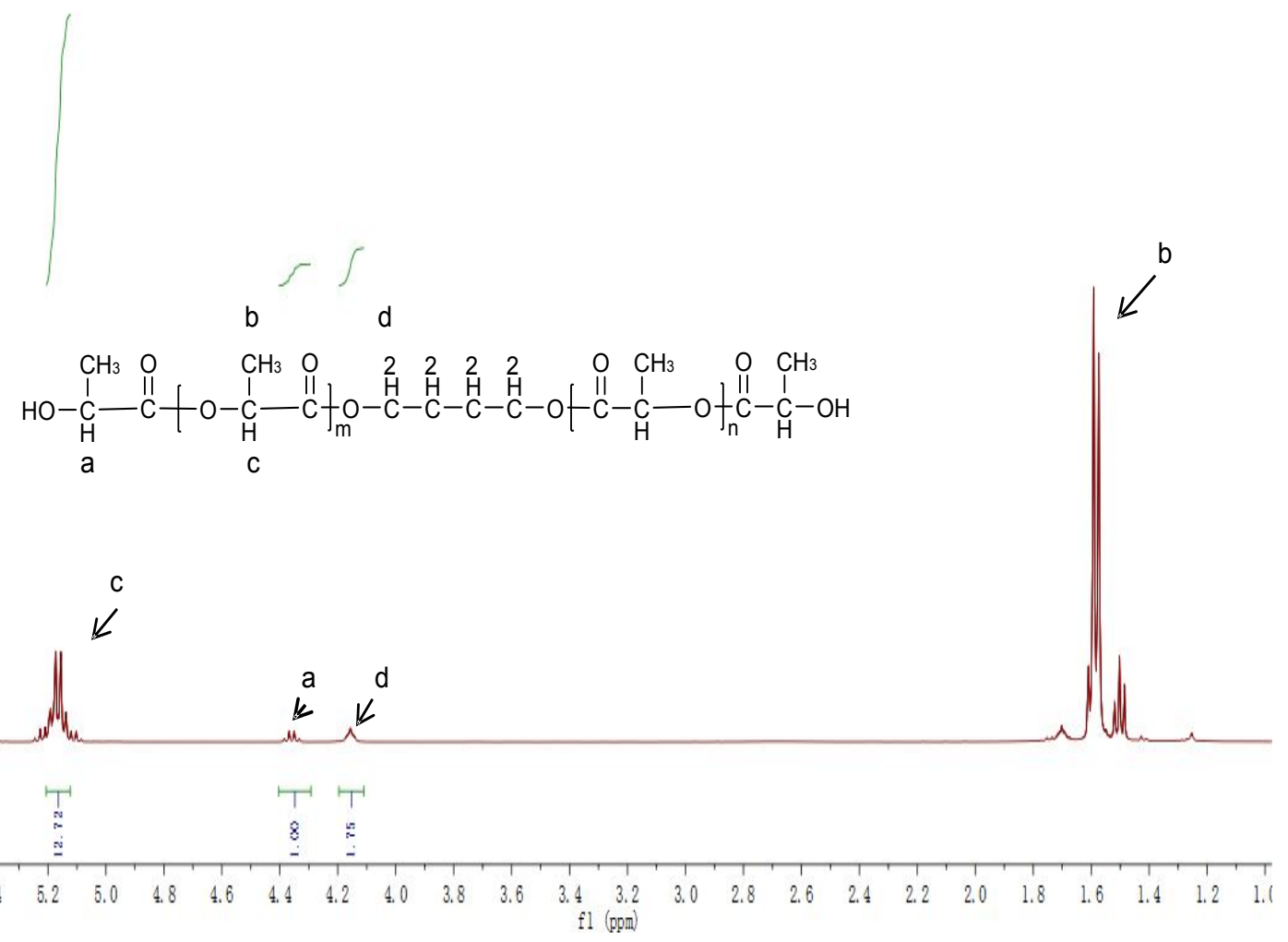

(b) 


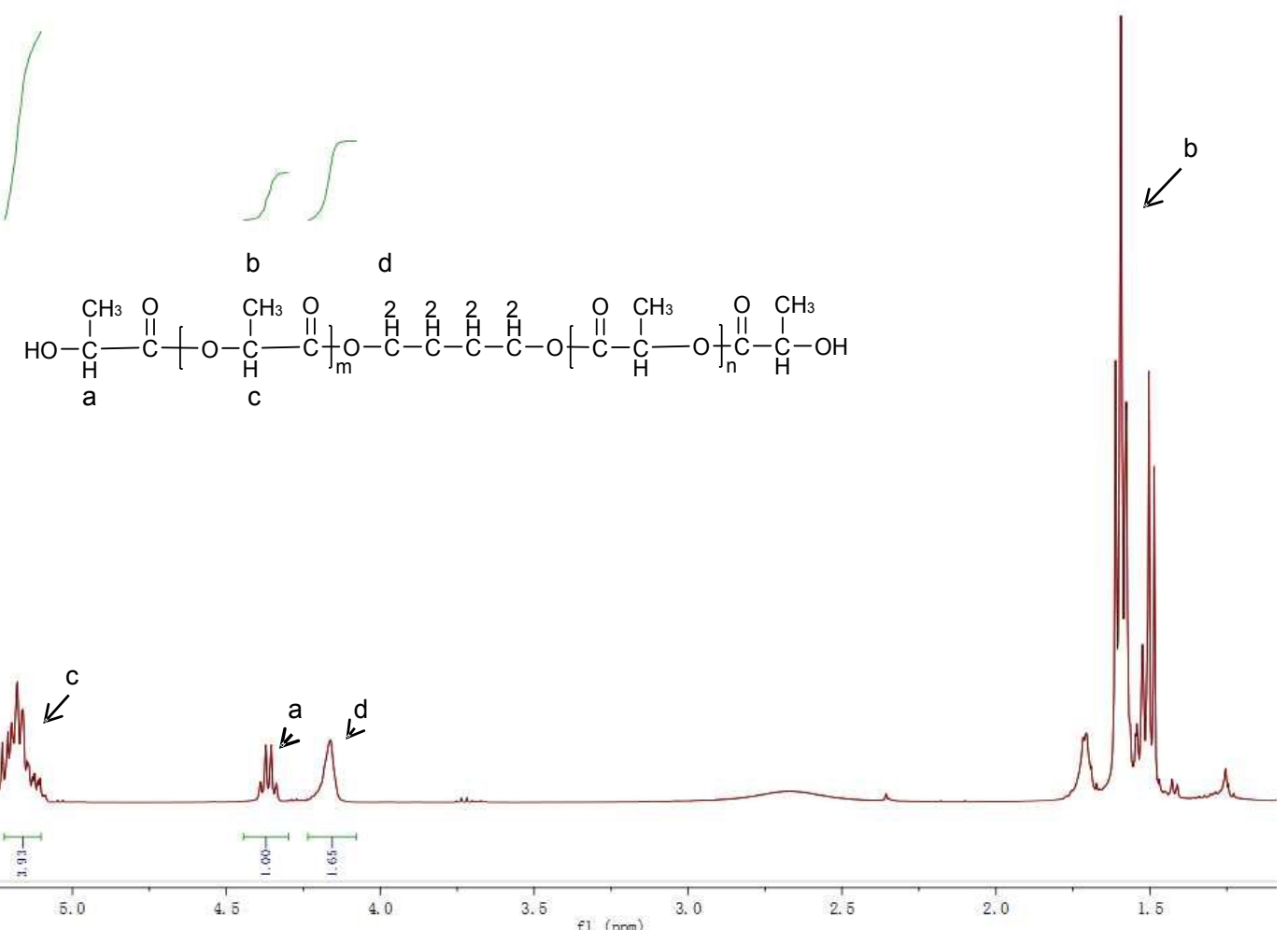

(c)

Figure S2. ${ }^{1} \mathrm{H}$ NMR spectra of PLA diol in $\mathrm{CDCl}_{3}$ ((a) PLA3000, (b) PLA2000, (c) PLA800)

According to the ${ }^{1} \mathrm{H}$ NMR spectra, the molecular weight of PLA diol was obtained by the formula, $M_{n}=\left(I_{c} / I_{a}+1\right) \times 72 \times 2+90$. In this formula, $I_{c}$ represents the peak area of the characteristic chemical shift of $\mathrm{H}$ belonging to the $\mathrm{CH}$ bond in the lactic acid group $\left(M_{n}=72\right.$ Dalton) which is the repeated unit in the PLA diol chain. $I_{a}$ indicates the peak area of the characteristic chemical shift of $\mathrm{H}$ belonging to the $\mathrm{CH}$ bond in the lactic acid group which is at both ends of the PLA diol chain. Moreover, the molecular weight of 1,4-butanediol is 90 Dalton.

Hence, we processed detailed calculation to obtain the molecular weight of PLA diol, and the results were as follows.

PLA3000 $\mathrm{M}_{\mathrm{n}}=(19.27 / 1+1) \times 72 \times 2+90=2998.88$ Dalton 
PLA2000 $\mathrm{M}_{\mathrm{n}}=(12.72 / 1+1) \times 72 \times 2+90=2065.68$ Dalton

PLA800 $\mathrm{M}_{\mathrm{n}}=(3.93 / 1+1) \times 72 \times 2+90=799.92$ Dalton 